\title{
Convergência de renda nos municípios do estado do Paraná: uma análise empírica no período 2002-2015
}

\author{
Income convergence in the municipalities of the state of Paraná an empirical \\ analysis in the period 2002-2015
}

\section{Geovani Aparecido de Oliveira David', Leandro Garcia Meyer", Michel Augusto Santana da Paixão"II}

\begin{abstract}
Resumo
Este trabalho tem como objetivo buscar evidências da existência de convergência de renda para os municípios do estado do Paraná, tanto em nível estadual como pela divisão em mesorregiões, no período de 2002 a 2015. Para tanto, foram aplicados os testes de $\beta$-convergência absoluta, condicional e a hipótese de $\sigma$-convergência, utilizando dados do Instituto Paranaense de Desenvolvimento Econômico e Social (IPARDES). Em nível estadual, os resultados indicaram que houve $\beta$-convergência absoluta e condicional, com os municípios mais pobres apresentando taxas de crescimento superiores aos municípios mais desenvolvidos. Esses resultados foram fortalecidos pelo teste de $\sigma$-convergência, pois a dispersão da renda per capita reduziu-se significativamente no período analisado. Para as mesorregiões, com exceção do Noroeste paranaense, também foram constatadas evidências de convergência. Por fim, embora o crescimento econômico tenha agido positivamente na redução das desigualdades, destaca-se a grande concentração dos municípios nos estratos de baixa renda, revelando que as disparidades ainda são expressivas no cenário econômico paranaense.
\end{abstract}

Palavras-Chave: Crescimento Econômico; Convergência de Renda; Paraná

\begin{abstract}
This paper aims to find evidence of income convergence among municipalities from the state of Paraná. Convergence hypothesis were evaluated both at state level and at mesoregions levels, from 2002 to 2015. To accomplish that, tests of absolute and conditional $\beta$-convergence were applied and the $\sigma$-convergence hypothesis was analyzed using data from the Instituto Paranaense de Desenvolvimento Econômico e Social (IPARDES). At state level, results indicated that there was absolute and conditional $\beta$-convergence, i.e., the poorest municipalities showed higher growth rates than richest municipalities. These results were strengthened by $\sigma$-convergence test, for the per capita income dispersion reduced significantly during the analyzed period. For mesoregions, evidence of convergence was found also, except for the Northwest part of Paraná. Finally, although economic growth had contributed to reduce inequalities, high concentration within low-income municipalities stand out, revealing that disparities are still significant in Paraná economic scenario.
\end{abstract}

Keywords: Economic growth; Income Convergence; Paraná

\footnotetext{
I Universidade Estadual do Norte do Paraná, PR, Brasil - geovani.aod@gmail.com II Universidade Estadual do Norte do Paraná, PR, Brasil - leandro.meyer@gmail.com III Universidade Estadual do Norte do Paraná, PR, Brasil - michelfeiradesantana@gmail.com
} 


\section{Introdução}

Nas últimas décadas, o debate sobre a hipótese da convergência de renda tornou-se frequente na literatura que aborda o crescimento econômico. Ainda que o tema não seja consensual, pesquisas buscam, por meio de evidências empíricas, explicações para as diferenças de renda per capita ${ }^{1}$ entre as diversas economias do mundo. Além dessa questão, outro fato observado nesses tipos de trabalhos é de que nem sempre o crescimento econômico elimina ou reduz os diferenciais de renda per capita ao longo do tempo.

A hipótese da convergência de renda começa com o modelo de Solow (1956). Nele, o capital fixo é importante, sendo que os retornos decrescentes para os fatores de produção levariam as economias a convergirem para o mesmo nível de renda per capita após uma trajetória de longo prazo. Posteriormente, estudos empíricos associados à essa temática foram se desenvolvendo, compondo uma vasta literatura, com destaque para os trabalhos precursores desenvolvidos por Baumol (1986) e Barro e Sala-i-Martin (1992).

Essa abordagem é utilizada para descobrir se as diferenças de renda entre as economias diminuem com o tempo. Analisando essa questão para o estado do Paraná, objeto de análise do presente trabalho, o estudo assume particular relevância considerando que esse estado possui um certo nível de desenvolvimento, mas que ainda assim, apresenta disparidades de renda per capita que são acentuadas entre seus municípios e regiões. De acordo com os dados do IBGE (2018), este ocupa a $5^{\circ}$ posição em termos de representatividade econômica, tendo registrado um PIB a preços correntes de $\mathrm{R} \$ 376.959 .754$ no ano de 2015 , correspondendo a 6,29\% do PIB brasileiro. A renda per capita foi de R $\$$ 33.769 , superior a média nacional, que foi da ordem de $\mathrm{R} \$ 29.326$.

Porém, esse dinamismo da economia paranaense não se distribui uniformemente por todo o estado, que é marcado por desigualdades na geração de riquezas. Exemplos dessas disparidades podem ser percebidas ao se comparar a renda per capita do município de Indianópolis com a do município de Nova Olímpia, ambos da mesorregião Noroeste paranaense e que registraram números da ordem de, respectivamente, $R \$ 86.470$ e de $R$ \$ 11.661 no ano de 2015 . Outro caso é o município de Saudade de Iguaçu (da mesorregião Sudoeste), que possui uma renda per capita de R $\$$ 114.153, enquanto que o município de Guaraqueçaba (da região Metropolitana de Curitiba) alcançou o montante de R\$9.904 no mesmo ano (IPARDES, 2018).

Percebidas as disparidades no nível de renda dentro do estado, um aspecto relevante a ser analisado é se essas diferenças vêm se reduzindo com o decorrer do tempo. Diante desse contexto, o presente artigo analisa o cenário econômico e uma possível tendência de convergência da renda per capita no estado do Paraná, tanto em nível estadual quanto em nível desagregado, dado pela divisão em mesorregiões, abordando o período 2002-2015. De forma complementar, o estudo pretende verificar qual é a intensidade do processo de convergência, caso esta ocorra, e identificar o tempo necessário para que os municípios paranaenses reduzam pela metade as desigualdades de renda entre si.

O presente estudo também consiste em apresentar uma extensão e um aprofundamento da literatura empírica já discutida sobre a hipótese da convergência de renda, a qual vem sendo adotada em larga escala por pesquisadores das áreas de economia e correlatas. É importante destacar que para o próprio estado do Paraná há alguns estudos prévios, tais como os de Harfuch e Santos Filho (2008), Vieira et al. (2012), Raiher (2015) e Dias e Porsse (2016). Entretanto, as discussões sobre o assunto não foram encerradas e faz-se necessário uma análise que considere um período mais recente da economia paranaense. Ademais, ao focalizar uma abordagem amplamente discutida na teoria do crescimento econômico no âmbito regional e municipal, o artigo pode oferecer uma contribuição para orientar políticas públicas e potencializar estratégias de desenvolvimento dentro do estado.

Além desta introdução, a segunda seção contextualiza as discussões teóricas e alguns dos principais estudos empíricos sobre convergência de renda; a terceira seção delineia as questões metodológicas, expondo a base de dados e o modelo empírico utilizado na presente pesquisa; a quarta seção contém os resultados e, por fim, tem-se a seção com as considerações finais do artigo.

\section{Discussões teóricas e principais estudos empíricos sobre convergência de renda}

A hipótese de que as economias tendem ou não a convergir para o mesmo nível de renda per capita está contida na teoria do crescimento econômico. Em sentido geral, Gomes (2013, p. 29) destaca que "a convergência é uma tendência de diminuição progressiva no tempo das diferenças entre as rendas relativas das economias ricas e pobres”. Um dos precursores sobre essa hipótese foi o modelo de Solow (1956), dizendo que, no longo prazo, haveria convergência, com as economias mais pobres alcançando níveis de renda per capita equivalentes às economias mais ricas.

Algumas das características fundamentais desse modelo são os retornos decrescentes de escala para os fatores

1 Segundo Jones (2000), a renda per capita de uma economia pode ser medida utilizando como proxy o PIB per capita. Dessa forma, o PIB per capita será utilizado, neste trabalho, como referência de renda per capita para os municípios paranaenses. 
de produção e a hipótese de estado estacionário². Assim, a relação produto/trabalhador e capital/trabalhador inferior ao exigido pelo estado estacionário apresentariam crescimento per capita ao longo de uma trajetória de transição. Contudo, as taxas de crescimento dos respectivos produtos per capita dessas economias iriam se reduzir à medida que se aproximassem do estado estacionário e, consequentemente, ocorreria uma estagnação. Nesse sentido, nota-se uma tendência de as taxas de crescimento serem inversamente proporcionais ao estado estacionário, promovendo a convergência e fazendo o hiato entre as rendas per capita das economias ricas e pobres se reduzirem até que possam se mover para o mesmo nível no longo prazo (ROMER, 2012).

Conforme foram avançando os estudos empíricos sobre a temática, houve também um aprofundamento conceitual no que diz respeito à abordagem da convergência, com o surgimento de duas definições, que são a convergência absoluta e a convergência condicional (CASAGRANDE; HOECKEL; SANTOS, 2017). Na literatura internacional, o trabalho de Baumol (1986) buscou investigar a hipótese da convergência absoluta entre algumas nações. Essa hipótese, que a evidência empírica demonstrou ser pouco plausível entre economias nacionais tão díspares entre si, pressupõe que os países convergem para o mesmo estado estacionário com o decorrer do tempo. Baumol (1986) observou a existência de convergência absoluta para um grupo de 16 economias industrializadas, no período 18701979. Posteriormente, De Long (1988) criticou os resultados encontrados por Baumol (1986), apontando, dentre outras falhas, o viés de seleção dos Países analisados.

Já a convergência condicional incorpora variáveis de controle na análise que indica que os países convergem para o seu próprio nível de renda em estado estacionário. Barro e Sala-i-Martin (1992) encontraram evidências de convergência absoluta para os estados americanos entre 1880-1988. Todavia, no mesmo estudo, os autores observaram apenas convergência condicional em uma análise com 98 nações no período 1960-1985. Nesse sentido, concluíram que a convergência absoluta dentro de uma mesma nação pode ocorrer de forma mais apropriada, enquanto que a convergência condicional é mais robusta para análises que envolvem diferentes países, devido às distintas características estruturais das economias.

As abordagens empíricas sobre essas hipóteses também estão presentes no âmbito da economia brasileira, aparecendo em maior número após a década de 90 . Em geral, os trabalhos têm focado principalmente no comportamento da renda per capita entre os estados brasileiros, devido à dificuldade de obtenção de dados em um nível menos desagregado. Dentre eles, podem ser citados Ellery Jr. (1994), Ferreira e Diniz (1994), Ferreira e Ellery Jr. (1996), Azzoni et al. (2000), Ferreira (2000), Nunes e Nunes (2004) e Santos e Carvalho (2007), que identificaram um processo de convergência absoluta de renda per capita. Já em relação aos estudos que observaram convergência condicional, sugerindo que os Estados brasileiros estariam convergindo para o seu próprio nível de renda em estado estacionário, destacam-se os trabalhos de Abitante (2007), Barreto e Almeida (2008), Cravo e Soukiazis (2006), Resende (2011) e Silveira Neto e Azzoni (2011).

No que tange a análise de convergência acerca dos municípios brasileiros em sua totalidade, o número de trabalhos é bem inferior. A esse respeito, cabe citar Chagas e Toneto Júnior (2003), que constataram a existência de convergência para os municípios brasileiros no período 1980-1991, com as áreas de menor renda crescendo a taxas superiores a de renda inicial maior. Outro trabalho que alcançou destaque no âmbito municipal foi Coelho e Figueiredo (2007), que identificaram a formação de clubes de convergência entre 1970 e 2000. No trabalho, o clube de baixa renda foi formado predominantemente pelos municípios das Regiões Norte e Nordeste, enquanto que o outro, com nível de renda maior, foi formado basicamente pelos Municípios das Regiões Centro-Oeste, Sudeste e Sul.

Nos anos mais recentes, mais trabalhos tem sido desenvolvidos a fim de se obter evidências particulares e locais. Para o estado de Minas Gerais, Fontes e Alves (1999), por exemplo, observaram convergência condicional entre as macrorregiões mineiras no período de 1970 a 1995, utilizando regressões em nível cross-section. Já Perobelli, Ferreira e Faria (2007), recorrendo ao método da análise exploratória de dados espaciais, investigaram o comportamento do PIB per capita entre os municípios mineiros, tendo como objeto de análise o período 1975-2003. Os resultados não indicaram sinais de convergência, demonstrando um aumento nas disparidades regionais do estado nesse período.

Já Casagrande, Hoeckel e Santos (2017) avaliaram dados sobre o PIB per capita para os municípios do Rio Grande do Sul entre 2001 e 2013. Utilizando regressões em nível cross-section e técnicas econométricas espaciais, os autores encontraram evidências de convergência absoluta e condicional de renda no estado, sendo a convergência condicional mais robusta. Ainda no que se refere ao Rio Grande do Sul, Oliveira, Jacinto e Grolli (2008), por meio de regressões quantílicas, Porsse (2008), através da econometria espacial, e Fantinel (2013), usando os conceitos de cadeias de Markov, matrizes de transição e distribuições-limite, foram outros estudos que observaram convergência da renda per capita no estado, levando em consideração os períodos 1970-2001, 1970-2000 e 2001-2010, respectivamente.

No que diz respeito à questão da convergência de renda no Paraná, também é possível verificar alguns estudos. Harfuch e Santos Filho (2008) observaram um processo de convergência absoluta para as 39 microrregiões do estado entre 1970 e 2002, através de regressões cross-section. Vieira et al. (2012), por meio da análise exploratória de dados

2 O estado estacionário constitui uma situação onde todas as variáveis do modelo crescem a taxas constantes, sendo o estado para o qual as economias convergem no longo prazo. 
espaciais, verificaram convergência de renda absoluta e condicional entre os municípios paranaenses no período 1999-2006. De forma similar, Raiher (2015), analisando o período 1995-2009, e Dias e Porsse (2016), analisando o período 2000-2010, constataram uma tendência à redução das disparidades entre as regiões e municípios paranaenses.

Para a região Nordeste, também há estudos para alguns estados. Barreto e Almeida (2009), por exemplo, utilizaram efeitos fixos com dependência espacial e encontraram convergência condicional do PIB per capita no Ceará entre 1996 e 2003. Cunha (2008), através de efeitos espaciais na análise de convergência regional, observou o mesmo processo para os municípios maranhenses no período 1991-2010. Já Silva Junior (2011) estudou o caso da economia alagoana no período 2002-2007. Por meio de regressões quantílicas, os resultados apontaram convergência condicional superior à absoluta dentro de Alagoas. Fernandes, Justo e Rocha (2017), através de regressões em nível cross-section e técnicas espaciais, também constataram convergência condicional superior à absoluta para os municípios do Rio Grande do Norte entre 1991-2014.

Outros estudos recentes abordando esse tema foram o de Mendoza (2009), Silva et al. (2010), Tavares (2011), Carvalho e Carvalho (2012), Mendes, Nishimura e Rodrigues (2013), Gonçalves (2014), Barbosa e Barreto (2015) e Silva Junior e Figueiredo (2017). Em todos esses trabalhos, seja observando a convergência absoluta ou a condicional, foi possível observar redução nos diferenciais de renda nos municípios dos estados de Roraima, do Acre, da Paraíba, do Pará, de Santa Catarina, do Espírito Santo, da Bahia e do Mato Grosso do Sul, respectivamente.

Após essa revisão da literatura pertinente ao assunto, é possível verificar uma variedade de objetos de estudo e diferentes metodologias adotadas. Pode-se notar, ainda, que a grande maioria dos resultados encontrados não são correlacionados entre si de forma clara, sendo que algumas evidências apontam que as economias convergem para diferentes níveis renda per capita em estado estacionário; outras evidências indicam que algumas economias estão convergindo para o mesmo nível de renda per capita; já algumas apontam para um processo de divergência, com as economias tendendo a apresentar um aumento na disparidade de renda. Nesse contexto, contribuindo com a literatura do crescimento econômico em âmbito estadual, o presente estudo atualiza o debate sobre a hipótese de convergência, tendo como objeto de análise os municípios do estado do Paraná no período 2002-2015.

\section{Metodologia}

\section{Base de dados}

Os dados coletados para os municípios paranaenses foram retirados do Instituto Paranaense de Desenvolvimento Econômico e Social (IPARDES) e do Atlas do Desenvolvimento Humano no Brasil (ATLAS). Na análise, foram considerados os 399 municípios do estado, assim como a divisão dos mesmos segundo suas 10 mesorregiões, para observar o comportamento da renda per capita e uma possível tendência de convergência em algumas regiões específicas. As 10 mesorregiões que compõem o estado do Paraná são: Centro Ocidental (25 municípios), Centro Oriental (14 municípios), Centro Sul (29 municípios), Metropolitana de Curitiba (37 municípios), Noroeste Paranaense (61 municípios), Norte Central (79 municípios), Norte Pioneiro (46 municípios), Oeste Paranaense (50 municípios), Sudeste Paranaense (21 municípios) e Sudoeste Paranaense (37 municípios). As mesorregiões foram definidas conforme a classificação do Instituto Brasileiro de Geografia e Estatística (IBGE).

O período amostral abordado compreende os anos de 2002 e 2015. A variável dependente em estudo é a taxa de crescimento da renda per capita (PIB per capita), construída como a razão entre a renda per capita de 2015 e a renda per capita do ano de 2002. A variável explicativa, na análise da convergência absoluta, é a renda per capita do período inicial, e, nesse caso, o ano de 2002. Assim como feito pelos estudos de Mendoza (2009) e de Casagrande, Hoeckel e Santos (2017), destaca-se que ambas as variáveis (variável dependente e independente) estão em logaritmo natural (Ln), proporcionando um melhor ajuste ao modelo.

Já na análise envolvendo a convergência condicional, além da renda per capita do ano inicial (2002) como variável explicativa, serão introduzidas outras características socioeconômicas municipais importantes para a dinâmica do crescimento econômico, tais como: Taxa de Analfabetismo (\%), IDH Educação, percentual (\%) dos ocupados com Ensino Superior Completo (ESC), IDH Longevidade, Proporção de Pobres (\%) e densidade demográfica. Essas variáveis, com exceção da densidade demográfica, tem como base o ano de 2000, uma vez que as disponibilidades desses dados estão atreladas ao censo do Programa das Nações Unidas para o Desenvolvimento (PNUD). Assim, apesar da certa defasagem temporal (2 anos) e considerar os valores obtidos para 2000 no modelo como a dotação inicial, a inclusão dessas variáveis mostra-se uma alternativa bastante útil para controlar a situação de cada município no início do período analisado, pois visa diminuir o viés de variável omitida presente no teste de convergência absoluta ${ }^{3}$.

Com relação às variáveis utilizadas, a renda per capita (PIB per capita) corresponde ao valor do PIB do município

3 Esse procedimento se justifica com base nos estudos de Gazonato, Gomes e Reis (2014) e Casagrande, Hoeckel e Santos (2017), que utilizaram abordagens similares para analisar a convergência condicional. 
dividido pelo número de habitantes do mesmo. A Taxa de Analfabetismo (\%) diz respeito à proporção de analfabetos por município. Considera-se, aqui, a faixa etária de 15 anos ou mais. O IDH Educação é medido pela composição de dois subíndices, que são a escolaridade da população adulta e o fluxo escolar da população jovem. O percentual (\%) dos ocupados com Ensino Superior Completo mostra a proporção dos ocupados que já concluíram a graduação do Ensino Superior. O IDH Longevidade, por sua vez, representa o número médio de anos que as pessoas devem viver. A Proporção de Pobres (\%) considera o percentual de indivíduos com renda domiciliar inferior a $\mathrm{R} \$ 140,00$ mensais, a preços de agosto de 2010. E, por fim, a densidade demográfica mostra como a população se distribui pelo território, sendo determinada pela razão entre a população e a área de determinado município (IPARDES, 2018; ATLAS, 2018).

\section{Modelo empírico}

Apesar da existência de diferentes metodologias e conceitos empregados na literatura referente ao processo de convergência, para atender as finalidades do presente estudo, adotou-se o método tradicional de regressões com dados em corte transversal (cross-section). Segundo Greene (2011), esse tipo de análise diz respeito ao estudo da dependência de uma variável, a variável dependente, em relação a uma ou mais variáveis, que são as variáveis explicativas ou explanatórias, sendo que neste tipo de regressão os dados para análise foram extraídos ou coletados em um determinado momento no tempo.

Portanto, a escolha deste método se justifica pelo fato de se estar usando dados para os municípios paranaenses em dois determinados momentos (2002 e 2015). Já no que se refere aos critérios de classificação dos conceitos de convergência, os trabalhos empíricos também não seguem um padrão homogêneo na literatura, conforme destaca Gomes (2013). A esse respeito, os conceitos mais relevantes aplicados são os de $\beta$-convergência absoluta e condicional, $\sigma$-convergência e a hipótese de clubes de convergência (DUARTE, 2011). À exceção dos clubes de convergência, os demais conceitos mencionados serão utilizados para testar a hipótese de convergência nos municípios paranaenses.

Partindo-se da hipótese de $\beta$-convergência absoluta, esta indica que as economias mais pobres tendem a apresentarem taxas de crescimento da renda per capita superiores as taxas de crescimento das economias mais ricas, o que levaria as economias a convergirem para o mesmo estado estacionário no longo prazo. Nesse sentido, a teoria considera que as taxas de crescimento são determinadas pelo nível inicial de renda de cada economia, desconsiderando outras condições socioeconômicas iniciais (CASAGRANDE; HOECKEL; SANTOS, 2017). Tal hipótese é derivada do modelo de Solow (1956) e é apropriada para regiões que apresentam grande mobilidade de recursos e contam com características socioeconômicas semelhantes.

Por outro lado, a hipótese de $\beta$-convergência condicional é utilizada na literatura ao considerar que as economias possuem diferenças significativas em suas condições socioeconômicas iniciais. Nesse caso, essa teoria procura incorporar algumas variáveis de controle na análise, sendo que essas variáveis utilizadas fariam as economias convergirem para o seu próprio estado estacionário. Dessa forma, no processo de convergência condicional, mesmo que as economias menos desenvolvidas apresentem taxas de crescimento superiores as mais desenvolvidas, é possível que essas economias convirjam para um nível menor de renda per capita no longo prazo (TAVARES, 2011).

Além desses testes, há também o conceito de $\sigma$-convergência. Para Matos Filho, Silva e Carvalho (2012, p. 71) esse conceito "diz respeito à dispersão do produto per capita do conjunto de economias. Nesse caso, a convergência se dará se for observada queda na dispersão do produto per capita, o que indica que as economias estão se aproximando".

\section{Testes de $\beta$-convergência e $\sigma$-convergência}

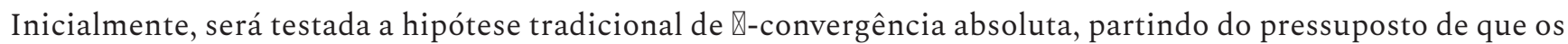
municípios paranaenses formam um grupo homogêneo com características socioeconômicas semelhantes e convergem para o mesmo estado estacionário. As abordagens analíticas seguiram os estudos desenvolvidos por Barro e Sala-i-Martin (1992) e Casagrande, Hoeckel e Santos (2017). No primeiro teste ( $\beta$-convergência absoluta), adotando-se um modelo de regressão linear simples e utilizando o método dos Mínimos Quadrados Ordinários (MQO), a taxa de crescimento da renda per capita (variável dependente) é estimada em relação à renda per capita inicial (variável explicativa), conforme segue na equação (1).

$$
\frac{1}{\mathrm{~T}} \operatorname{Ln}\left(\frac{\mathrm{Y}_{\mathrm{i}, \mathrm{t}}}{\mathrm{Y}_{\mathrm{i}, 0}}\right)=\beta_{1}+\beta_{2} \operatorname{Ln}\left(\mathrm{Y}_{\mathrm{i}, 0}\right)+\mu_{\mathrm{i}}
$$

Onde: é a renda per capita dos municípios paranaenses em 2002 (período inicial); é a renda per capita dos municípios paranaenses em 2015 (período final); e são os coeficientes estimados; T refere-se ao número de anos entre o período analisado (13 anos); e é o erro aleatório. 
$\mathrm{Na}$ equação (1), o lado esquerdo do sinal de igualdade corresponde à taxa de crescimento no período abordado.

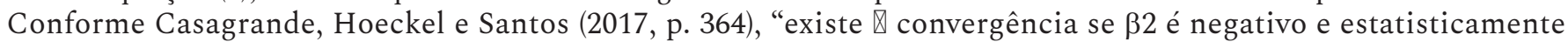
significativo, já que, nesse caso, a taxa média de crescimento do PIB per capita entre o período inicial e o período final é negativamente correlacionada com o nível inicial do PIB per capita".

Essa abordagem ( $\beta$-convergência absoluta) é procedente, pois ao analisar a existência de convergência ou não de renda dentro do estado do Paraná, supõe-se que há uma diminuição nas diferenças socioeconômicas e características estruturais que poderiam existir em uma análise envolvendo outras economias nacionais. Contudo, o estudo também será aprofundado testando a hipótese de convergência condicional, tendo como objetivo tornar os resultados mais robustos. Nesse sentido, estende-se a análise da existência de convergência nos municípios paranaenses, modificando a equação (1) e acrescentando algumas variáveis de controle que representam as condições de cada município no início do período analisado. Para tanto, tem-se a equação (2) como base para o teste de $\bigotimes$-convergência condicional.

$$
\frac{1}{\mathrm{~T}} \operatorname{Ln}\left(\frac{\mathrm{Y}_{\mathrm{i}, \mathrm{t}}}{\mathrm{Y}_{\mathrm{i}, 0}}\right)=\beta_{1}+\beta_{2} \operatorname{Ln}\left(\mathrm{Y}_{\mathrm{i}, 0}\right)+\sum_{i=1}^{\kappa} \beta_{k} X_{i, t}+\mu_{\mathrm{i}}
$$

Em que: Em que: representa um grupo de $k$ variáveis de controle. Assim, a estimação de $\beta$-convergência condicional acrescenta como variáveis explicativas o nível inicial de renda per capita e esse conjunto de variáveis.

Após estimar o valor do coeficiente de $\beta_{2}$ na regressão, é possível calcular também outros dois conceitos, que são a velocidade de convergência e a Meia-Vida (MV). O primeiro mede com qual intensidade ocorre à velocidade de aproximação entre as economias com renda inicial menor e as economias com renda inicial maior. O segundo diz respeito ao tempo necessário para que as economias em estudo reduzam pela metade as desigualdades de renda per capita entre si, caso permaneçam as mesmas taxas de crescimento observadas no período em questão (GOMES, 2013). Conforme Casagrande, Hoeckel e Santos (2017), a velocidade de convergência e a MV podem ser expressas pelas equações (3) e (4), respectivamente.

$$
\theta=\frac{\operatorname{Ln}\left(\beta_{2}+1\right)}{(-k)}
$$

Onde: é a velocidade de convergência; $\beta_{2}$ é o coeficiente estimado pelas equações (1) e (2); e $k$ é o número de anos entre o período em estudo (13 anos).

$$
\mathrm{MV}=\frac{\operatorname{Ln}(2)}{\theta}
$$

Em que: MV (Meia-Vida) - tempo necessário; é a velocidade de convergência, estimada a partir da equação 3; Ln (2) é o Logaritmo Natural de 2.

Por fim, tem-se o teste de $\bigotimes$-convergência, que pode ser testado mediante a análise do Coeficiente de Variação (CV), dado pela razão entre o desvio-padrão e a média aritmética da renda per capita (FONTES; ALVES, 1999). O CV pode ser obtido por meio da equação (5).

$$
\mathrm{CV}=\frac{\mathrm{S}}{\overline{\mathrm{X}}} \times 100
$$

Sendo que S é o desvio-padrão; é a média aritmética dos dados (renda per capita); e CV é o Coeficiente de Variação. Valores iguais a zero para o CV indicam uma perfeita igualdade na distribuição na renda, enquanto valores mais próximos de 1 significam uma renda per capita mais concentrada. 


\section{Resultados e discussões}

\section{Análise de $\beta$-convergência}

Definidos os métodos a serem utilizados, esta seção busca analisar o resultado da hipótese de convergência de renda para os municípios paranaenses, dentro do período abordado. Para tanto, a análise inicia-se na Figura 1, onde é apresentado, por meio do diagrama de dispersão, uma indicação prévia dos resultados esperados, relacionando o nível inicial de renda e as respectivas taxas médias de crescimento dos 399 municípios do estado. A linha vermelha representa a reta de regressão de ajustamento dos dados, obtida a partir do método de MQO, e os pontos azuis são as observações da amostra.

Figura 1 - Taxa média de crescimento da renda per capita (2002-2015) e renda per capita inicial dos municípios paranaenses

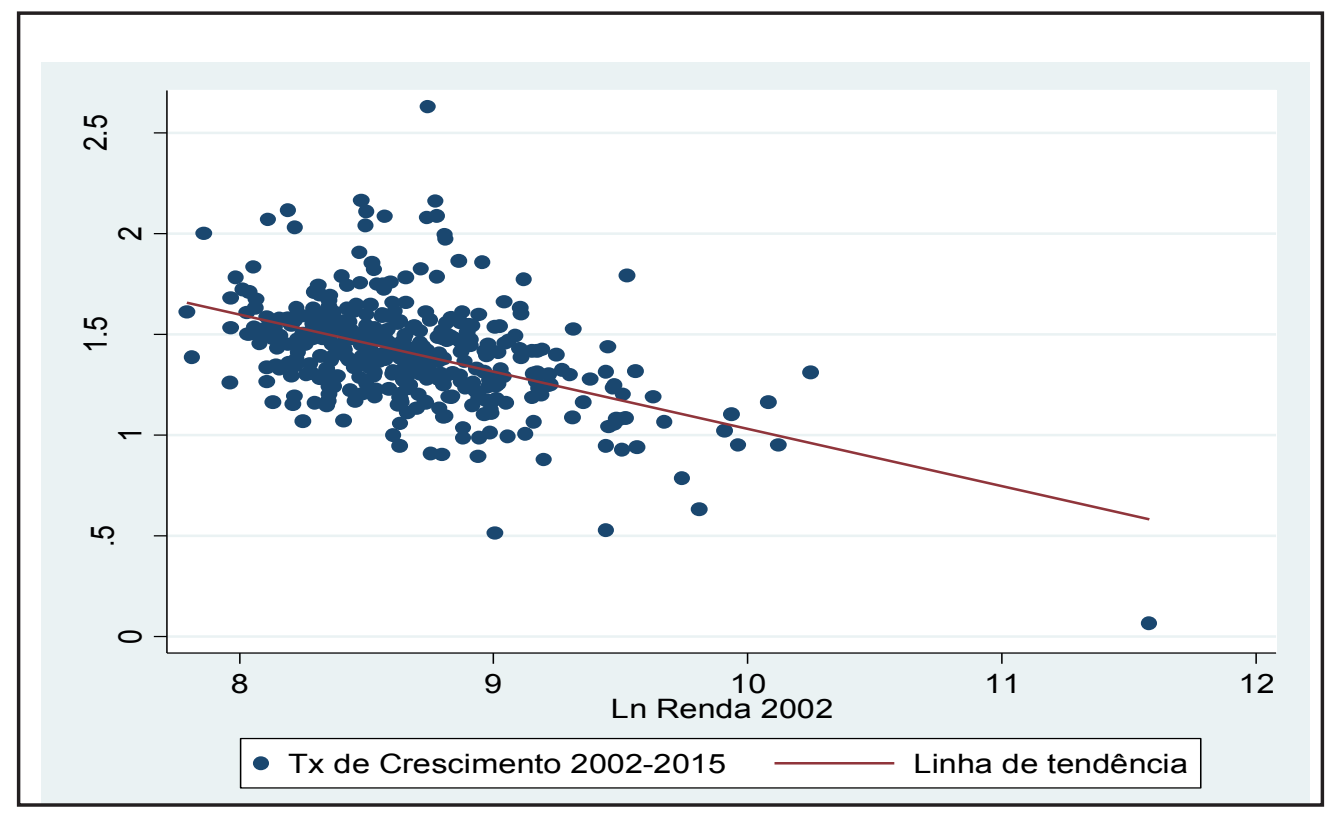

Fonte: Elaborada pelos autores a partir de resultados da pesquisa (2018).

Neste caso, é possível perceber que a relação entre a variável dependente (taxa de crescimento) e a variável explicativa (renda per capita inicial) é negativamente inclinada, indicando que, quanto menor o valor do logaritmo natural da renda per capita inicial, maiores são as taxas de crescimento do período. Sendo assim, há evidências da existência de convergência absoluta nos municípios paranaenses, e o crescimento econômico per capita observado agiu sobre as disparidades de renda. No âmbito das mesorregiões, notam-se resultados semelhantes ${ }^{4}$. Para uma melhor compreensão do comportamento dessas taxas de crescimento, os resultados da regressão encontram-se dispostos na Tabela 1. A coluna 2 apresenta os resultados para todos os municípios do Paraná, enquanto as colunas 3-12 apresentam as estimações desagregadas por mesorregiões.

$\mathrm{Na}$ Tabela 1, observa-se, em nível estadual, que o sinal do coeficiente associado ao nível inicial de renda ( $\beta 2)$ mostra-se coerente com a teoria $(-0,284)$, indicando que o crescimento da renda per capita observado no período foi maior nas economias municipais mais pobres. Também na Tabela 1, é possível verificar que a velocidade de convergência () encontrada para o período foi de aproximadamente $2,60 \%$. A partir desse resultado, o coeficiente de MV indica que serão necessários aproximadamente 27,01 anos para que os municípios paranaenses possam eliminar metade das desigualdades de renda existentes.

Vale ressaltar que esses resultados estão de acordo com alguns estudos em âmbito estadual citados anteriormente na literatura. Como exemplos desses estudos que encontraram evidências particulares para alguns estados, Casagrande, Hoeckel e Santos (2017) constataram uma taxa de convergência de 2,65\% e uma Meia-Vida (MV) de 26,20 anos para os municípios do estado do Rio Grande do Sul, no período 2001-2013. Silva et al. (2010) encontraram uma taxa de convergência e uma Meia-Vida para os municípios do estado do Acre de, respectivamente, 2,17\% e 33 anos, levando em consideração o período 1991-2000. Fernandes, Justo e Rocha (2017) observaram uma taxa anual de convergência de 2,58\% e uma Meia-Vida de 31,30 anos para os municípios do estado do Rio Grande do Norte, entre 1991 e 2014. Já Carvalho e Carvalho (2012), analisando a hipótese de convergência para os municípios do estado do

4 Por restrições de espaço, as Figuras para cada uma das 10 Mesorregiões não foram apresentadas ao longo do texto. Contudo, elas podem ser visualizadas no anexo, ao final deste trabalho. 
Pará entre 1970 e 2000, encontraram uma taxa anual de convergência de 2,08\%, o que resultou em uma Meia-Vida de aproximadamente 33,38 anos.

Para melhor entender o processo de convergência no Paraná, assim como observar uma possível tendência convergente da renda per capita entre municípios de uma mesma região, estimou-se a equação (1) para cada uma das mesorregiões do estado (colunas 3-12). Nesta análise desagregada, as estimações também apontam para uma redução nas disparidades econômicas em termos per capita, pois os coeficientes comprovam uma relação negativa entre o nível da renda inicial e a taxa de crescimento, indicando $\beta$-convergência absoluta. Contudo, para a mesorregião Noroeste paranaense (Norop), embora o coeficiente encontrado seja negativo $(-0,218)$, os resultados devem ser analisados com parcimônia, visto que a regressão não apresentou significância estatística.

Já no que diz respeito à velocidade de convergência, as evidências apontam que essa não ocorre de forma homogênea no âmbito das mesorregiões. As taxas encontradas variam de 1,2\%, na região Metropolitana de Curitiba (Metc) até 8,7\% no Sudeste paranaense (Sudep). Nas mesorregiões Centro-Ocidental (Cocp), Centro-Oriental (Corp), Centro-Sul (Csp), Noroeste Paranaense (Norop), Norte Central (Norc), Norte Pioneiro (Norp), Oeste paranaense (Oep) e Sudoeste paranaense (Sudop), as taxas de convergência são da ordem de 4,3\%, 4,9\%, 3,5\%, 1,9\% 2,8\%, 3,3\%, $1,2 \%$ e $3,7 \%$, respectivamente. Essas diferenças podem estar ligadas ao número de municípios que fazem parte de cada uma das mesorregiões. O Sudeste paranaense (Sudep), por exemplo, é composto por 14 municípios, enquanto o Norte Central (Norc) é constituído por 79 municípios.

Associados à velocidade de convergência, encontram-se os resultados de MV (em anos) em nível regional. Para o conjunto de municípios da mesorregião Oeste paranaense (Oep), Metropolitana de Curitiba (Metc) e Noroeste paranaense, a MV foi superior à média estadual, sendo que as desigualdades observadas entre os municípios dessas mesorregiões se reduziriam pela metade em 58,13 anos, 57,54 anos e 36,71 anos, respectivamente, o que implica em um processo de convergência bastante lento nessas regiões. Para as demais, o tempo de MV encontra-se abaixo da média do Paraná, o que indica que as diferenças de renda estão sendo corrigidas de forma mais rápida do que em âmbito estadual.

Tabela 1 - Teste de $\beta$-convergência absoluta da renda per capita para os municípios do Paraná no período $2002-2015$

\begin{tabular}{|c|c|c|c|c|c|c|c|c|c|c|c|}
\hline Variáveis & $\operatorname{Pr}$ & Cocp & Corp & Csp & Metc & $p$ & re & Norp & Oep & ep & Sud \\
\hline Ln rpc 2002 & 0,284 & $-0,431$ & $-0,472$ & $-0,369$ & 0,145 & $-0,218$ & 0,303 & $-0,352$ & $-0,144$ &, 677 & $-0,385$ \\
\hline Erro ${ }^{(1)}$ & 0,026 & 0,075 & 0,147 & 0,063 & 0,052 & & & 22 & & & 62 \\
\hline Constante & 3,866 & 5,195 & & 4,3 & & & & & & & 826 \\
\hline Erro ${ }^{(2)}$ & 0,230 & 0,661 & 1,331 & 0,545 & 0,460 & 1,093 & 0,626 & 0,787 & 0,625 & 1,681 & 0,541 \\
\hline oservaçõ & & 25 & 14 & 27 & 37 & 61 & 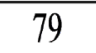 & & 50 & 21 & 37 \\
\hline R-quad & 0,224 & 0,589 & 0,461 & 0,556 & 0,179 & 0,047 & 0,185 & 0,249 & 0,080 & 0,393 & 0,524 \\
\hline R-ajus & & & 0 & & 0,156 & 0,031 & & 32 & 0,061 & 361 & 0,510 \\
\hline F-stat & 90 & 33,01 & 10,28 & 84 & 7,63 & 2,90 & 17,48 & 14,61 & 4,18 & 2,32 & 38,49 \\
\hline P-valor & 000 & 0,000 & 0,008 & 0,000 & 0,009 & 0,094 & 0,000 & 0,000 & 0,046 & 0,002 & 0,000 \\
\hline 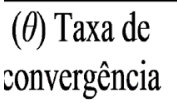 & 26 & 0,043 & 0,049 & 0,035 & 012 & 0,019 & 0,028 & 0,033 & 0,012 & 0,087 & 0,037 \\
\hline Meia-Vida &, 01 & 19,65 & 14,09 & 19,56 & 57,54 & 36,71 & 25,00 & 20,78 & 58,13 & 7,97 & 18,55 \\
\hline
\end{tabular}

Fonte: Elaborada pelos autores a partir dos resultados da pesquisa (2018).

Nota: (1) Erro-padrão de $\beta 2$ (Ln renda per capita 2002); (2) Erro-padrão da constante (intersecção).

Apesar das evidências empíricas terem sido robustas quanto à existência de uma possível tendência de convergência absoluta, outra possibilidade relacionada ao presente estudo equivale em testar a hipótese de convergência condicional para os municípios paranaenses. A esse respeito, na Tabela 2, são apresentados os resultados das estimativas da equação (2), que introduz variáveis de controle que representam aspectos socioeconômicos de cada município no período inicial. Porém, nas primeiras estimações, muitas das variáveis explicativas consideradas na equação (2) para controlar as diferenças estruturais entre os municípios não foram significativas. Dessa forma, o modelo foi restringido, com o objetivo de torná-lo mais parcimonioso e prevenir também problemas de multicolinearidade ${ }^{5}$, sendo que as variáveis de controle incluídas nas estimativas foram: Taxa de Analfabetismo (\%), que está representada pela sigla Tx_Analf; e o IDH Longevidade, representado pela sigla IDH_Long.

5 Em anexo, a Tabela A1 apresenta a análise de correlação para diversas variáveis explicativas. Ademais, também em anexo, a Tabela A2 contempla a estimação inicial, considerando as diversas variáveis explicativas do modelo irrestrito. 
Ainda no que refere à utilização da Taxa de Analfabetismo (\%) e do IDH Longevidade no modelo condicional restrito, destaca-se que a escolha por essas variáveis também é bastante plausível nos estudos relacionados à hipótese da convergência de renda. De acordo com a literatura do crescimento econômico, como Romer (1986), Lucas (1988) e Mankiw, Romer e Weil (1995), bem como algumas evidências empíricas para o caso brasileiro, tais como Ferreira (2000), Gomes (2013), Lau et. al. (1993) e Barreto e Almeida (2009), o nível de educação das pessoas é uma importante proxy para representar o estoque de capital humano, variável que influencia as taxas de crescimento da renda per capita das mais distintas economias. Já com relação ao IDH Longevidade, Silva, Fontes e Alves (2006), Vieira, Sonaglio e Carvalho (2008) e Casagrande, Hoeckel e Santos (2017) foram alguns dos estudos que constataram uma relação positiva entre esse índice e a taxa de crescimento da renda, o que também é de se esperar, visto que condições mais adequadas de saúde (uma das medidas sociais que sintetizam o IDH_Long) poderiam resultar em níveis melhores de produção.

Nesse sentido, os resultados apresentados na Tabela 2 demostram que, para todos os municípios do estado do Paraná, o coeficiente estimado da renda per capita inicial manteve-se negativo e significativo (-0,321). No entanto, quando comparado com a hipótese da convergência absoluta, o coeficiente encontrado é maior e, de modo geral, a inclusão das variáveis de controle acelera o processo de convergência de renda, sendo que a taxa de convergência condicional foi de 3,0\%, ocasionando uma Meia-Vida de aproximadamente 23,27 anos. Ademais, como já era previsto, a introdução da variável Taxa de Analfabetismo (Tx_Analf) na regressão obteve um coeficiente negativo $(-0,004)$, indicando que, quanto mais baixa for essa taxa, maior será o crescimento da renda per capita. Com relação ao resultado do IDH Longevidade (IDH_Long), o coeficiente dessa variável foi positivo $(0,653)$ e também apresentou o sinal previsto pela literatura. Isso sugere que a homogeneização do capital humano/nível de escolaridade e das condições de vida da população seriam condições necessárias para a equalização econômica no estado.

Para as mesorregiões, da mesma forma que para a convergência absoluta, constataram-se diferenças no que diz respeito à taxa de convergência e na Meia-Vida. A região Metropolitana de Curitiba (Metc) continua a apresentar a menor taxa, 1,2\% ao ano, que está associado a um tempo de Meia-Vida de 60,15 anos. A maior taxa de convergência está no Sudep paranaense, com um coeficiente de 10,30\% ao ano e uma Meia-Vida de 6,70 anos. Outro fato que chama a atenção nas estimativas da Tabela 2 é de que a inclusão das variáveis de controle diminui o coeficiente associado ao nível inicial de renda na região Metropolitana de Curitiba, reduzindo a taxa de convergência e aumentando o valor da Meia-Vida. Tal evidência aponta que a Taxa de Analfabetismo e o IDH Longevidade não foram significativos para explicar uma tendência convergente entre 2002-2015 nessa região, podendo existir outros fatores não modelados que estariam influenciando as taxas de crescimento municipais. Por outro lado, a inclusão de controles na regressão acelera de forma considerável a taxa de convergência na mesorregião Oeste paranaense, onde a Meia-Vida se reduziu para 31,25 anos.

Tabela 2 - Teste de $\beta$-convergência condicional (modelo restrito) da renda per capita para os municípios do Paraná no período 2002-2015

\begin{tabular}{|c|c|c|c|c|c|c|c|c|c|c|c|}
\hline Variáveis & Pr & Соcp & Corp & Csp & Metc & Norop & Norc & Norp & Oep & Sudep & Sudop \\
\hline $\operatorname{Ln} r p c 2002$ & $-0,321$ & $-0,461$ & $-0,507$ & $-0,407$ & $-0,139$ & $-0,223$ & $-0,386$ & $-0,457$ & $-0,251$ & $-0,739$ & $-0,423$ \\
\hline Erro ${ }^{(1)}$ & 0,030 & 0,089 & 0,202 & 0,069 & 0,064 & 0,141 & 0,085 & 0,105 & 0,091 & 0,193 & 0,058 \\
\hline Constante & 3,766 & 4,833 & 2,438 & 3,574 & 2,295 & 4,411 & 5,572 & 5,335 & 3,525 & 7,048 & 5,178 \\
\hline Erro & 0,413 & 1,246 & 2,520 & 1,120 & 1,009 & 1,986 & 1,076 & 1,414 & 1,116 & 2,376 & 1,222 \\
\hline Tx_Analf & $-0,004$ & $-0,003$ & 0,012 & $-0,003$ & 0,002 & $-0,004$ & $-0,014$ & $-0,017$ & $-0,009$ & $-0,035$ & $-0,033$ \\
\hline Erro & 0,003 & 0,011 & 0,016 & 0,011 & 0,007 & 0,014 & 0,007 & 0,009 & 0,007 & 0,025 & 0,012 \\
\hline IDH_Long & 0,653 & 0,904 & 4,377 & 1,803 & 0,268 & $-1,298$ & $-0,774$ & 0,363 & 0,304 & 1,437 & 0,528 \\
\hline Erro & 0,412 & 1,288 & 2,771 & 1,222 & 1,140 & 1,690 & 0,946 & 1,311 & 0,922 & 2,434 & 1,321 \\
\hline Jbservações & 399 & 25 & 14 & 29 & 37 & 61 & 79 & 46 & 50 & 21 & 37 \\
\hline R-quadrado & 0,240 & 0,603 & 0,574 & 0,605 & 0,182 & 0,057 & 0,229 & 0,313 & 0,142 & 0,478 & 0,628 \\
\hline R-ajustado & 0,234 & 0,546 & 0,446 & 0,558 & 0,108 & 0,007 & 0,198 & 0,264 & 0,086 & 0,386 & 0,594 \\
\hline F-stat & 41,62 & 10,62 & 4,49 & 12,77 & 2,45 & 1,14 & 7,41 & 6,37 & 2,54 & 5,18 & 18,59 \\
\hline P-valor & 0,000 & 0,000 & 0,031 & 0,000 & 0,038 & 0,120 & 0,000 & 0,000 & 0,008 & 0,001 & 0,000 \\
\hline $\begin{array}{l}(\theta) \text { Taxa de } \\
\text { :onvergência }\end{array}$ & 0,030 & 0,047 & 0,054 & 0,040 & 0,012 & 0,019 & 0,038 & 0,047 & 0,022 & 0,103 & 0,042 \\
\hline Meia-Vida & 23,27 & 14,60 & 12,75 & 17,22 & 60,15 & 35,69 & 18,46 & 14,74 & 31,25 & 6,70 & 16,38 \\
\hline
\end{tabular}

Fonte:Elaborada pelos autores a partir da pesquisa (2018)

Nota: (1) Erro-padrão de $\beta 2$ (Ln renda per capita (2002); (2) Erro-padrão da constante (intersecção); (3) Erro-padrão da taxa de analfabetismo; (4) Erro-padrão do IDH longevidade 


\section{Análise de $\sigma$-convergência}

Além das hipóteses de $\beta$-convergência absoluta e condicional, outra alternativa muito utilizada na literatura para mensurar se o hiato entre determinadas regiões está aumentando ou diminuindo é através do estudo da dispersão da renda per capita ( $\sigma$-convergência), como sugerido por Sala-i-Martin (1995). Para verificar essa hipótese, é necessário analisar o Coeficiente de Variação (CV), sendo que a $\sigma$-convergência ocorrerá se houver uma queda na dispersão da renda per capita, o que implica dizer que as economias em estudo estariam se aproximando e se tornando mais homogêneas. Dessa forma, pode-se afirmar, conforme Monfort (2008), que os testes de $\beta$-convergência procuram detectar processos de catching-up ${ }^{6}$, enquanto o teste de $\sigma$-convergência analisa uma possível redução nas desigualdades. Ainda conforme o autor, os dois conceitos, embora sejam diferentes, estão intimamente relacionados, sendo que a $\beta$-convergência se caracteriza como um fator necessário, porém não suficiente para a ocorrência de $\sigma$-convergência.

Na Tabela 3, conforme a equação (5), são apresentados os valores do Coeficiente de Variação (CV) para a renda per capita dos municípios do estado do Paraná e para as mesorregiões. Em nível estadual, em consonância com os resultados obtidos para os testes de $\beta$-convergência, confirma-se a hipótese de $\sigma$-convergência, pois os números evidenciam um menor grau de desigualdade da renda em 2015 do que em 2002. Ou seja, os resultados encontrados sugerem que, apesar da distribuição de renda ainda ser muito díspar no estado, há um processo de declínio no nível dessa dispersão. Para as mesorregiões, com exceção do Noroeste paranaense, também houve redução do Coeficiente de Variação (CV), sendo que no ano de 2015 as rendas municipais estavam mais equalizadas do que no ano de 2002.

Tabela 3 - Teste de $\sigma$-convergência para os municípios do Paraná no período 2002-2015

\begin{tabular}{cccc}
\hline Região & CV em 2002 (\%) & CV em 2015 (\%) & Evolução do CV (\%) no período \\
\hline Pr & 90,13 & 47,18 & $-42,95$ \\
Cocp & 40,67 & 27,72 & $-12,95$ \\
Corp & 54,53 & 35,07 & $-19,46$ \\
Csp & 68,84 & 45,80 & $-23,04$ \\
Metc & 78,70 & 71,73 & $-6,37$ \\
Norop & 36,82 & 49,53 & 12,71 \\
Norc & 38,20 & 37,22 & $-0,98$ \\
Norp & 32,01 & 29,71 & $-2,30$ \\
Oep & 43,57 & 38,69 & $-4,88$ \\
Sudep & 33,81 & 28,30 & $-5,51$ \\
Sudop & 198,07 & 57,87 & $-140,21$ \\
\hline
\end{tabular}

Fonte: Elaborada pleos autores a partir da pesquisa (2018).

É importante ressaltar, entretanto, que embora os testes de convergência sejam dotados de grande solidez teórica e empírica, sua análise não possibilita afirmar que todas as economias consideradas estão seguindo a mesma tendência, ou se, ainda, há algum município excluído desse processo. Nesse contexto, os testes até aqui apresentados demonstram as tendências gerais da economia paranaense entre 2002 e 2015, onde as rendas municipais se tornaram mais homogêneas e o grau de desigualdade se reduziu.

Com o intuito de ampliar o horizonte de estudo e verificar também a dinâmica econômica individual dos municípios paranaenses, a última análise desenvolvida no presente trabalho foi direcionada para compreender a evolução da distribuição de renda no período abordado, classificando os municípios em estratos e tomando como base de comparação a média da renda per capita estadual. Assim, acompanhando a literatura e seguindo principalmente os estudos prévios ${ }^{7}$ de Costa (2009), Zuchetto (2016) e Silva, Fontes e Alves (2006), optou-se por dividir os municípios do estado do Paraná em cinco classes $(\mathrm{k}=5$ ), sendo: Muito Pobre (abaixo de $40 \%$ da média estadual); Pobre (entre $40 \%$ e $80 \%$ da média estadual); Renda Média (entre $80 \%$ e $120 \%$ da média estadual); Rico (entre $120 \%$ e $160 \%$ da média estadual; e Muito Rico (acima de $160 \%$ da média estadual).

6 Em economia, designa-se por catching-up o processo onde as economias em desenvolvimento se aproximam das mais desenvolvidas. Isto ocorre porque, teoricamente, em razão da lei dos rendimentos marginais decrescentes, as economias mais desenvolvidas crescem mais lentamente. Por outro lado, as economias em desenvolvimento apresentam níveis de produtividade e possíveis taxas de crescimento mais elevadas. Para mais detalhes, ver Solow (1956).

7 Costa (2009) utilizou tal estratificação para analisar o comportamento da renda per capita nos estados brasileiros entre 1970 e 2005 ; Zuchetto (2016) nos estados e municípios brasileiros entre 1999 e 2013; e Silva, Fontes e Alves (2006) nos municípios e microrregiões do estado de Minas Gerais entre 1970 e 2000 . 


\section{Classificação dos municípios paranaenses em estratos de renda per capita}

As modificações ocorridas na distribuição de renda para os municípios do estado entre 2002 e 2015 podem ser visualizadas na Figura $2^{8}$. Em linhas gerais, constata-se um território de grandes disparidades, principalmente em 2002 , onde $8,52 \%$ dos municípios eram muito pobres. Em 2015, o total foi de 4,01\%. Os municípios com maiores problemas foram Laranjal (Csp), Campo Magro (Metc), Cerro Azul (Metc), Doutor Ulysses (Metc), Guaraqueçaba (Metc), Piraquara (Metc), Marumbi (Norc), Sapopema (Norp) e Diamante do Sul (Oep), que se mantiveram relativamente muito pobres, não demonstrando nenhuma tendência à superação dessa situação. Do restante, $73,53 \%$ que eram muito pobres em 2002 tornaram-se pobres em 2015, sugerindo certa inclinação à convergência e uma conjuntura mais favorável de renda, embora se tenham mantido em uma posição precária em relação à média estadual. Desse grupo, três municípios pertencem ao Cocp; cinco ao Csp; dois pertencem a Metc; quatro se localizam no Norop; seis no Norc e cinco no Norp.

Com relação aos municípios pobres, este foi o grupo que menos se modificou. Em 2002, 64,41\% dos municípios pertenciam a esse estrato, enquanto que no ano de 2015 o total foi de $62,41 \%$. Desse grupo, $78,60 \%$ dos municípios se mantiveram estacionados, sugerindo estagnação dessas economias; do restante, $2,72 \%$ se tornaram muito pobres, $15,18 \%$ convergiram para a situação de renda média, $2,72 \%$ para o estrato rico e $0,78 \%$ dos municípios alcançaram uma melhor dinâmica de crescimento, tornando-se relativamente muito ricos, sendo eles Indianópolis (Norop) e Sabáudia (Norc). Por outro lado, os municípios de Inácio Martins (Csp), Almirante Tamandaré (Metc), Altônia (Norop), Inajá (Norop), Nova Olímpia (Norop), Xambrê (Norop) e Curiúva (Norop) foram os que apresentaram baixo dinamismo econômico, convergindo para a situação muito pobre.

Dos municípios de renda média, 19,05\% estavam inseridos nesse estrato de renda no ano de 2002. Em 2015, 25,31\% foram considerados de renda média (o que seria compatível com a hipótese de convergência, onde todos deveriam dirigir-se para a média). Durante o período abordado, 27,63\% dos municípios de renda média tiveram um desempenho ruim, declinando economicamente e se tornando relativamente pobres, $64,47 \%$ se mantiveram na posição inicial e 7,89\% obtiveram bons resultados, convergindo para o estrado de renda dos municípios ricos, sendo eles: Rancho Alegre D' Oeste (Cocp), Douradina (Norop), Ibiporã (Norc), Sertaneja (Norp), Entre Rios do Oeste (Oep) e Bom Sucesso do Sul (Sudop).

No grupo dos municípios ricos do estado, $5,26 \%$ se concentravam nesse estrato de renda no período inicial, enquanto que em 2015 o total foi de 5,76\%. Dentre os que eram considerados ricos em 2002, o município de Antônio Olinto (Sudep) apresentou baixo dinamismo econômico, convergindo para a situação pobre. Em situação oposta, o município de Cafelândia (Oep) elevou ainda mais o seu nível de renda per capita, convergindo para o estrato muito rico. Dos restantes desse grupo, 52,38\% dos municípios convergiram para o estrato de renda média e $38,10 \%$ se mantiveram estacionados na mesma posição, não apresentado tendência de mudanças.

Quanto ao grupo dos muito ricos, 2,76\% e 2,51\% dos municípios do estado do Paraná pertenciam a esse estrato de renda nos anos de 2002 e 2015, respectivamente. Entre 2002 e 2015, os municípios de Arapoti (Corp) e Quedas do Iguaçu (Csp) convergiram para o estrato de renda média, e Balsa Nova (Metc) e Diamante do Norte (Norop) convergiram para o grupo dos municípios ricos. Por outro lado, $63,64 \%$ dos municípios que estavam no grupo dos muito ricos no período inicial se mantiveram nessa posição, dos quais fazem parte Carambeí (Corp), Mangueirinha (Csp), Araucária (Metc), Piên (Metc), São José dos Pinhais (Metc), Capitão Leônidas Marques (Oep) e Saudade do Iguaçu (Sudop).

Por fim, ainda no tocante à Figura 2, confirma-se uma tendência de redução dos contrastes referentes às disparidades de renda per capita municipais. De modo geral, o mapeamento das taxas de crescimento indica concentração de resultados superiores à média estadual nos municípios menos favorecidos economicamente. Ademais, $62,91 \%$ dos municípios do estado registraram crescimento per capita acima da média do Paraná, enquanto que 37,09\% apresentaram taxas de crescimento abaixo da média.

Nesse sentido, em resumo, existem evidências da existência de convergência de renda nos municípios do Paraná, resultado esse também encontrado em algumas mesorregiões do estado. Contudo, pelo que parece, a convergência condicional se mostrou mais adequada para explicar a dinâmica do crescimento econômico no período, com os municípios convergindo para seus próprios estados estacionários, no qual os mais distantes do equilíbrio crescem a taxas superiores, porém para um nível menor de renda. O cenário apresentado também demonstrou que os municípios continuam concentrando-se, em sua maioria, nos estratos de renda mais baixos. Em 2002, os classificados nos estratos muito pobres e pobres eram 72,93\%, e em 2015 a soma desses dois estratos contabilizou 66,42\%. O reagrupamento decorreu, em grande parte, de uma mudança de municípios no estrato muito pobre para pobre, o que indica que essas municipalidades apresentam baixos rendimentos e deverão manter o atraso relativo ao longo do tempo em relação aos municípios mais desenvolvidos.

8 Em anexo, as Tabelas A3, A4, A5 e A6 complementam os resultados ilustrados na Figura 2. Também em anexo, a Figura A2 demonstra a divisão das dez mesorregiões do estado do Paraná. 
Para as mesorregiões, o comportamento econômico da renda sugere que as diferenças mais acentuadas estão na região Metropolitana de Curitiba, no Noroeste e no Oeste paranaense, que possuem enorme heterogeneidade no nível de desenvolvimento de suas economias, contendo municípios em todos os grupos de renda. Por outro lado, o Centro-Ocidental e o Sudeste paranaense se apresentam como as regiões que parecem ter as menores diferenças, com seus municípios se inserindo em apenas dois estratos no ano de 2015. Já no que diz respeito às taxas de crescimento, com exceção da região Metropolitana de Curitiba, as demais mesorregiões registraram um maior número de municípios com crescimento per capita acima do que abaixo da média estadual.

Figura 2 - Distribuição dos municípios do estado do Paraná segundo os estratos de renda per capita (R\$) e taxa de crescimento entre $2002^{(1)}$ e $2015^{(2)}$

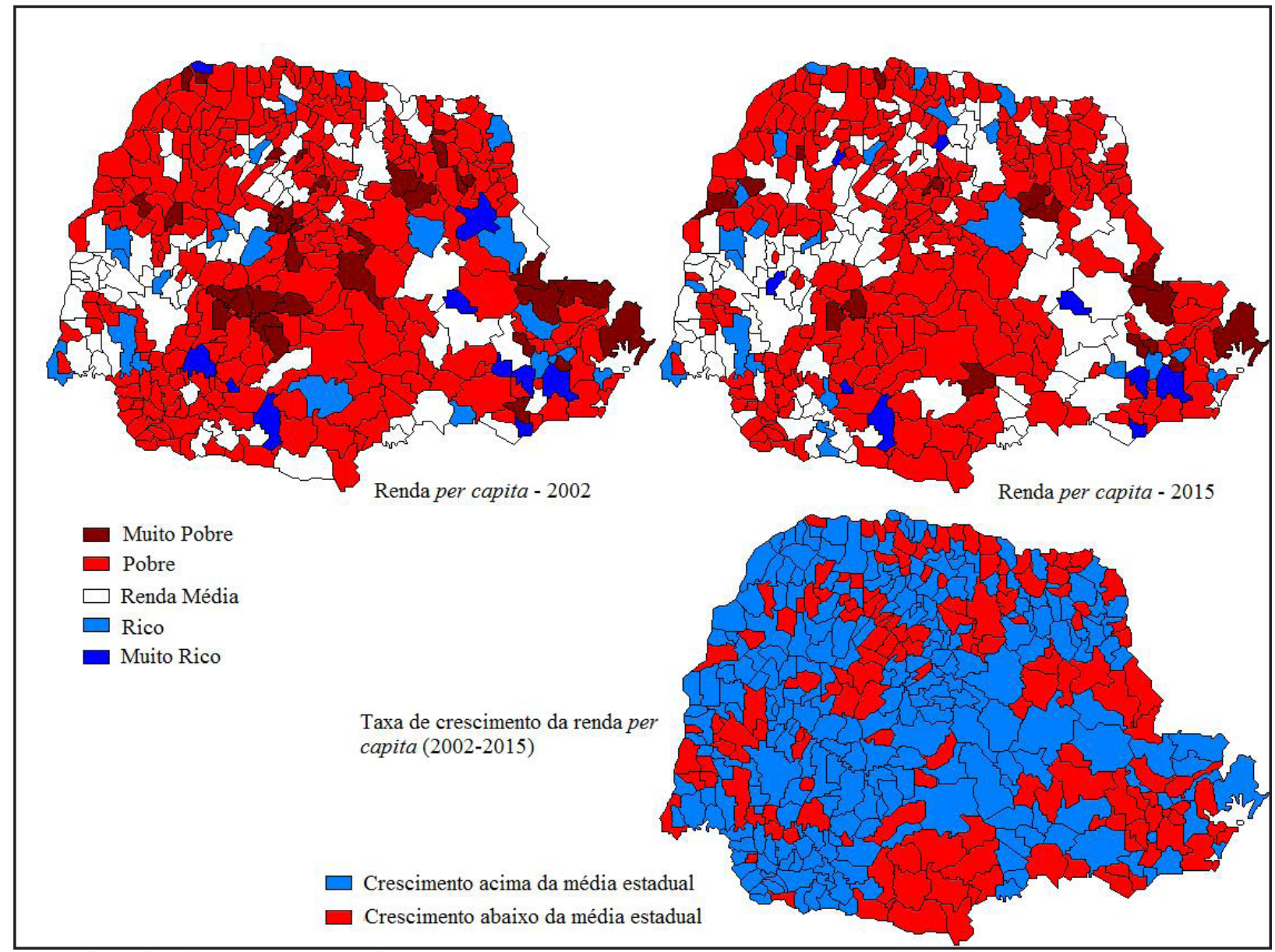

Fonte: Adaptada pelos autores a partir de IPARDES (2018).

Notas: (1) R\$ 9.005 foi a rpc do PR em 2002; (2) R\$33.769 foi a rpc do PR em 2015.

\section{Considerações finais}

A presente pesquisa buscou uma melhor compreensão do processo de crescimento econômico e das hipóteses de convergência da renda per capita para os municípios do estado do Paraná, no período 2002-2015. Com esse intento, utilizou-se inicialmente a divisão municipal do estado conforme a classificação do IBGE, no qual há 399 municípios, e para uma segunda análise os municípios foram reagrupados conforme as dez mesorregiões geográficas em que estão divididos.

Como síntese geral, este estudo gerou importantes constatações. O primeiro fato verificado foi que o estado do Paraná possui uma das economias regionais mais dinâmicas no cenário nacional, ocupando posição de destaque quando comparado ao desempenho de outros estados. Contudo, internamente, seu desenvolvimento socioeconômico é bastante diferenciado entre suas regiões e municípios. Por isso, enquanto algumas áreas são muito desenvolvidas, apresentando uma economia pujante e dinâmica, outras são pobres, estagnadas economicamente e contribuem com 
uma pequena parcela da renda estadual. Tal fato constitui um entrave considerável à superação das desigualdades e evidencia a necessidade de se desenvolver políticas públicas que conduzam para a desconcentração produtiva regional, fortalecendo a geração de empregos e renda.

Os resultados dos testes de convergência também forneceram importantes considerações sobre o comportamento da renda per capita no período abordado. Em nível estadual, é possível afirmar que houve um processo de convergência, com os municípios menos desenvolvidos apresentando taxas de crescimento superiores às taxas de crescimento dos mais desenvolvidos. Tal conclusão pode ser inferida através das regressões para os testes de $\beta$-convergência e por meio da análise do Coeficiente de Variação (CV). A taxa de convergência absoluta encontrada foi de $2,60 \%$, a taxa de convergência condicional foi de $3,0 \%$ e o Coeficiente de Variação (CV) se reduziu 42,95\%, confirmando a hipótese de $\sigma$-convergência para os municípios paranaenses.

Em âmbito regional, encontraram-se evidências de convergência, tanto absoluta quanto condicional, para as mesorregiões Centro Ocidental, Centro Oriental, Centro Sul, Metropolitana de Curitiba, Norte Central, Norte Pioneiro, Oeste, Sudeste e Sudoeste paranaense. Já para a mesorregião Noroeste paranaense, os resultados não possibilitaram afirmar que as diferenças tenham se reduzido. Considerando a expressiva disparidade, as evidências apontam também que a velocidade com que o processo de convergência vem ocorrendo é baixa na região Metropolitana de Curitiba e no Oeste paranaense, onde a Meia-Vida encontrada para que as diferenças de renda fossem reduzidas significativamente foi maior do que a verificada para a média estadual.

Outro resultado interessante obtido neste trabalho diz respeito à distribuição dos municípios paranaenses conforme seus estratos de renda per capita. Quando comparado com a renda estadual, pode-se concluir, a partir da tendência apresentada no período, que embora as desigualdades tenham sido amenizadas, não ocorreu grande concentração de municípios no estrato de renda média, que seria compatível com a hipótese de convergência absoluta. Pelo contrário, os resultados indicam que os municípios convergem para diferentes estados estacionários, confirmando a hipótese de convergência condicional. Assim, certo nível de desigualdade será mantido, e isto ocorrerá porque a renda per capita inicial não é o único fator que influencia na taxa de crescimento dos municípios. Como já mencionado, outros fatores determinam essa taxa, dentre eles o capital humano e a qualidade de vida, aqui testados a partir das variáveis Taxa de Analfabetismo (\%) e IDH Longevidade,

O período analisado talvez reflita uma das limitações deste estudo, necessitando-se assim de uma expansão do intervalo. Todavia, isso se justifica quando se tem o objetivo de acompanhar as recentes transformações da economia paranaense. Destaca-se, por fim, que antes de esgotar as possibilidades da hipótese de convergência de renda no estado do Paraná, o presente trabalho abre esse debate, deixando a temática à espera de novas abordagens e considerações, onde recomenda-se para pesquisas futuras a incorporação da econometria espacial, haja vista a relevância de se incluir os efeitos espaciais na análise desse importante problema de pesquisa.

\section{Referências}

ABITANTE, K. G. Desigualdade no Brasil: um estudo sobre convergência de renda. Pesquisa e Debate, São Paulo, v. 18, n. 2(32) p. 155-169, 2007.

ATLAS - Atlas do Desenvolvimento Humano no Brasil. Base de Dados. Rio de Janeiro, PNUD, IPEA, Fundação João Pinheiro. Disponível em: http://atlasbrasil.org.br/2013/ Acesso em: 21 mai. 2018.

AZZONI, C. et al. Geografia e Convergência de Renda entre os Estados Brasileiros. Brasília, DF: IPEA, 2000.

BARBOSA, A, O.; BARRETO, R. C. S. Uma análise sobre o crescimento econômico dos municípios do estado da Bahia: um teste da hipótese de convergência de renda. Revista Economia \& Região, Londrina, v. 3, n. 1, p.57-80, jan. 2015.

BARRETO, R. C. S. ALMEIDA, E. S. A contribuição do capital humano para o crescimento econômico e convergência espacial do PIB per capita no Ceará. In: Holanda, M. C.; Carvalho, E. B. S.; Barbosa, M. P. (Org.). Economia do Ceará em Debate 2008. Fortaleza-CE: IPECE, 2009.

BARRO, R.; SALA-I-MARTIN, X. “Convergence”. Journal of Political Economy, v. 100, n. 2, p. 223-251, 1992.

BAUMOL, W. J. Productivity growth, convergence, and welfare: what the long-run data how. American Economic Review, 54, p. 1072-1085, 1986. 
CARVAlHO, D. F.; CARVAlHO, A. C. Crescimento Econômico Endógeno e Convergência de Renda per capita dos Municípios do Estado do Pará: 1970-2000. Cadernos CEPEC, v. 01, p. 01-21, 2012

CASAGRANDE, D. L.; HOECKEL, P. H. de O.; SANTOS, Cezar Augusto Pereira dos. Convergência do PIB per capita no Rio Grande do Sul: uma análise de 2001 a 2013. Revista Brasileira de Estudos Regionais e Urbanos, v. 11, n. 3, p. 358-383, 2017.

CHAGAS, A. L. S.; TONETO JR, R. Fatores determinantes do crescimento local - Evidências a partir de dados dos municípios brasileiros para o período 1980-1991. Pesquisa e Planejamento Econômico, v. 33, n. 2, 349-385, 2003.

COELHO, R. L. P.; FIGUEIREDO, L. Uma análise da hipótese da convergência para os municípios brasileiros. Revista Brasileira de Economia, v. 61, n. 3, p. 331-352, 2007.

COSTA, Leticia Magalhães da. Análise do processo de convergência de renda nos estados brasileiros: 19702005. 2009. 47 f. Dissertação (Mestrado) - Curso de Economia, Escola de Pós-graduação em Economia - EPGE Fundação Getúlio Vargas, Rio de Janeiro, 2009.

CRAVO, T.; SOUKIAZIS, E. O capital humano como fator determinante para o processo de convergência entre os estados do Brasil. In: ENCONTRO REGIONAL DE ECONOMIA: NORDESTE, 2006, Fortaleza. Estratégias de Desenvolvimento Regional. Fortaleza: Anpec, 2006. Disponível em: http://edi.bnb.gov.br/content/aplicacao/ Eventos/forumbnb2006/docs/o.pdf. Acesso em 17 Mai. 2018.

CUNHA, A. S. A. Crescimento econômico no Estado do Maranhão: uma análise espacial dos dados para o período de 1991 a 2000. 68 f. Dissertação (Mestrado) - Curso de Pós-graduação em Economia, Universidade Federal de Viçosa, Minas Gerais, 2008.

DE LONG, B. Productivity Growth, Convergence and Welfare: Comment. The American Economic Review, Pittsburgh, PA, v. 78, n. 5, p. 1138-1154, 1988. Disponível em:<https://eclass.uoa.gr/modules/document/file.php/ ECON206/Course\%20material/Delong\%20Convergence\%20AER\%201988.pdf>. Acesso em: 17 mai. 2018.

DIAS, F.; PORSSE, A. Convergência de renda nos municípios paranaenses, no período 2000-10: uma abordagem de econometria espacial. Ensaios FEE, v. 37, n. 2, p. 581, 2016.

DUBIEL, S. A.; RAIHER, A. P.; Desenvolvimento econômico dos municípios do Paraná: evolução e determinantes. Informe Gepec, Toledo, v. 17, n. 2, p. 6-22, jul. 12.

ELLERY JR, R. G. Crescimento e convergência de renda entre os Estados brasileiros. 59 f. Dissertação (Mestrado) - Escola de Pós-graduação em Economia (EPGE) - Fundação Getúlio Vargas, Rio de Janeiro, 1994.

FANTINEL, V. D. Convergência de renda entre os municípios gaúchos: uma análise markoviana - 200110. Indicadores Econômicos FEE. Porto Alegre, v. 44, n. 1, p. 9-16, 2016.

FERNANDES, D. P.; JUSTO, W. R.; ROCHA, R. M.. Análise da Convergência de Renda para Municípios do Rio Grande do Norte entre 1991-2014. In: I Latin American and Caribbean Regional Science Association Congress, 2017, São Paulo. Anais. I Latin American and Caribbean Regional Science Association Congress, 2017.

FERREIRA, A. Convergence in Brazil: recent trends and long run prospects. Applied Economics, London, v. 32, n. 4, p.479-489, 2000.

FERREIRA, A. H. B.; DINIZ, C. C. Convergência entre as rendas per capita estaduais no Brasil. Belo Horizonte: UFMG/Cedeplar, 1994. 27p. (Texto para Discussão, n.79).

FERREIRA, P. C.; ELLERY JR, R. G. Convergência entre a renda per capita dos estados brasileiros. Revista de Econometria, v. 16, n. 1, p.83-104, 1996.

FONTES, R.; ALVES, L.F. Desigualdades inter-regionais e convergência de renda em Minas Gerais. Revista de 
Economia da UNA, v. 1, n. 9, p. 4-21, 1999.

GAZONATO, M. C.; GOMES, A. L.; REIS, R. R. de G. Desigualdade de Renda no Brasil: uma análise da convergência da renda per capita dos estados para o período de 1994 e 2010. Revista de Economia, Curitiba, v. 40 , n. 2, p. 81-104, 2014.

GOMES, R. R. Convergência de renda: uma análise para os Estados nordestinos no período de 1995-2009. 97 f. Dissertação (Mestrado) - Curso de Mestrado Profissional em Desenvolvimento Regional e Gestão de Empreendimentos Locais, Universidade Federal de Sergipe, São Cristóvão, 2013.

GONÇALVES, R. B. Estudo empírico da hipótese de convergência entre os Municípios do Estado do Espírito Santo. 45 f. Dissertação (Mestrado) - Curso de Ciências Contábeis, Fundação Instituto Capixaba de Pesquisas em Contabilidade, Economia e Finanças - Fucape, Vitória, 2014.

GREENE, W H. Econometric Analysis. 5ㅡㄹ. Índia: Pearson Education, 2011.

HARFUCH, L.; SANTOS FILHO, J. I. Convergência do PIB per capita das Microrregiões Paranaenses entre 1970-2002. A Economia em Revista, Maringá, v. 16, n. 2, p.5-16, jul. 2008.

IBGE - Instituto Brasileiro de Geografia e Estatística. Estatísticas - Base de dados. Disponível em: https:// cidades.ibge.gov.br. Acesso em: 17 mai. 2018.

IPARDES - Instituto Paranaense de Desenvolvimento Econômico e Social. Base de dados do Estado. Disponível em: http://www.ipardes.pr.gov.br. Acesso em: 17 mai. 2018.

IPARDES - Instituto Paranaense de Desenvolvimento Econômico e Social. Perfil avançado das Mesorregiões geográficas paranaenses. Disponível em: http://www.ipardes.gov.br. Acesso em: 17 mai. 2018.

JONES, C. I. Introdução à teoria do crescimento econômico. 3ª Ed. Rio de Janeiro: Campus, 2000.

LAU, L. J; JAMISON, D. T; LIU, S. RIVKIN, S. Education and economic growth: somecross-sectional evidence from Brazil: Journal of Development Economics, v. 41, p. 45-70, 1993.

LUCAS, R. E. On the mechanics of economic development. Journal Of monetary Economics, v.22, p. 3-42, 1988.

MANKIW, N. G; ROMER, D; WEIL, D. N. A contribution to the empirics of economic growth. The Quarterly journal of economics, v. 107, n. 2, p. 407-437, may, 1992.

MATOS FILHO, J. C.; SILVA, A. B. da.; CARVALHO, T. N. A convergência da renda nas microrregiões da Região Nordeste do Brasil. Economia e Desenvolvimento, Recife, v. 11, n. 2, p.67-86, 2012.

MENDES, K.; NISHIMURA, F. N.; RODRIGUES, M. de C. Análise de Convergência da Renda em Santa Catarina entre 2011 e 2012: PIB per capita, Espacialidade, Renda Pessoal e Demografia. Revista de Estudos Sociais, v. 16, n. 32, p.45-62, 2014.

MENDOZA, S. S. R. Convergência do Crescimento Econômico no Estado de Roraima. 80 f. Dissertação (Mestrado) - Curso de Ciências Econômicas, Universidade Federal do Rio Grande do Sul, Porto Alegre, 2009.

MONFORT, P. Convergence of EU regions: Measures and evolution. Working Paper European Commission Regional Policy, n. 01, 2008.

NUNES, R. C.; NUNES, S. P. P. O papel dos Fundos de Participação dos Estados - FPE - na convergência de renda per capita dos estados brasileiros. Revista de Economia e Estadística, Córdoba, v. 42, n. 2, p. 89-103, 2004.

OLIVEIRA, C. A. de.; JACINTO, P. de A.; GROLLI, P. A. Crescimento econômico e convergência com a utilização de regressões quantílicas: um estudo para os municípios do Rio Grande do Sul - 1970-01. Ensaios FEE, Porto Alegre, v. 28, p. 671-700, 2008. 
PEROBELLI, F. S.; FERREIRA, P. G. C; FARIA, W. R. Análise de convergência espacial do PIB per capita em Minas Gerais. Revista Brasileira de Estudos Regionais e Urbanos, Juiz de Fora, v. 1, n. 1, p. 85-113, 2007.

PORSSE, A. Dinâmica da desigualdade de renda municipal no Rio Grande do Sul: evidências da análise estatística espacial. Porto Alegre. 2008. (Texto para discussão FEE, nํ42).

RAIHER, A. P. Crescimento econômico e sua convergência no Estado do Paraná. Gestão \& Regionalidade (Online), v. 31, n. 92, p.163-150, 2015.

RESENDE, G. M. Multiple dimensions of regional economic growth: the Brazilian case, 1991 2000. Papers in Regional Science, v. 90, n. 3, p. 629-662, 2011.

ROMER, D. Advanced macroeconomics. 4ª Ed. EUA: Mc Graw Hill, 2012.

SALA-I-MARTIN, X. The classical approach to convergence analysis. Economic Journal, v. 106, n.437, p. 10191036, 1996.

SANTOS, C. M.; CARVALHO, F. M. A. Dinâmica das disparidades regionais da renda per capita nos estados brasileiros: uma análise de convergência. Revista Economia e Desenvolvimento, n.19, 2007.

SILVA, E; FONTES, R; ALVES, L. F. Crescimento e desigualdade de renda em Minas Gerais, Revista Econômica do Nordeste, v. 37, n. 1, p. 54-78, jan.-mar. 2006.

SILVA JUNIOR, E. A.; FIGUEIREDO, A. M. R Análise da convergência de renda entre os Municípios de Mato Grosso do Sul entre 1999 e 2012. Revista de Economia da UEG, v. 13, n. 1, p. 51-69, 2017.

SILVA, R. G. et al. Uma abordagem probabilística da convergência per capita de renda na década de noventa para o Acre. In: XLVIII Congresso da Sociedade Brasileira de Economia, Administração e Sociologia Rural, 2010, Campo Grande. Anais. XLVIII Congresso da Sociedade Brasileira de Economia, Administração e Sociologia Rural, 2010.

SILVA JUNIOR, G. G. Convergência de renda: uma análise para os municípios do estado de Alagoas. 71 f. Dissertação (Mestrado) - Curso de Curso de Pós-graduação em Economia Aplicada, Universidade Federal de Alagoas, Maceió, 2011.

SILVEIRA NETO, R. M.; AZZONI, C. R. Non-Spatial Policies and Regional Income Inequality in Brazil. Regional Studies, [S.1.], v. 45, p. 453-461, 2011.

SOLOW, R. M. “A Contribution to the Theory of Economic Growth.” Quarterly Journal of Economics, v.70, p.65-94, 1956.

TAVARES, M. B. Análise da dinâmica da renda per capita nos municípios paraibanos, no período de 1970 a 2008. Dissertação (Mestrado) - Curso de Ciências Econômicas, Universidade Federal da Paraíba, João Pessoa, 2011.

VIEIRA, F. L. et al. Convergência de Renda e Desenvolvimento Regional no Paraná (1999-2006). Informe Gepec, Toledo, v. 16, n. 1, p. 213-234, 2012.

ZUCHETTO, F. B. Convergência de renda para estados e municípios brasileiros: 1999 a 2013. Dissertação (Mestrado em Economia). Programa de Pós-Graduação em Economia, Universidade Federal do Rio Grande do Sul, Porto Alegre, 2016 


\section{Anexos}

Figura A1 - Taxa média de crescimento da renda per capita (2002-2015) e renda per capita inicial dos municípios paranaenses conforme suas mesorregiões

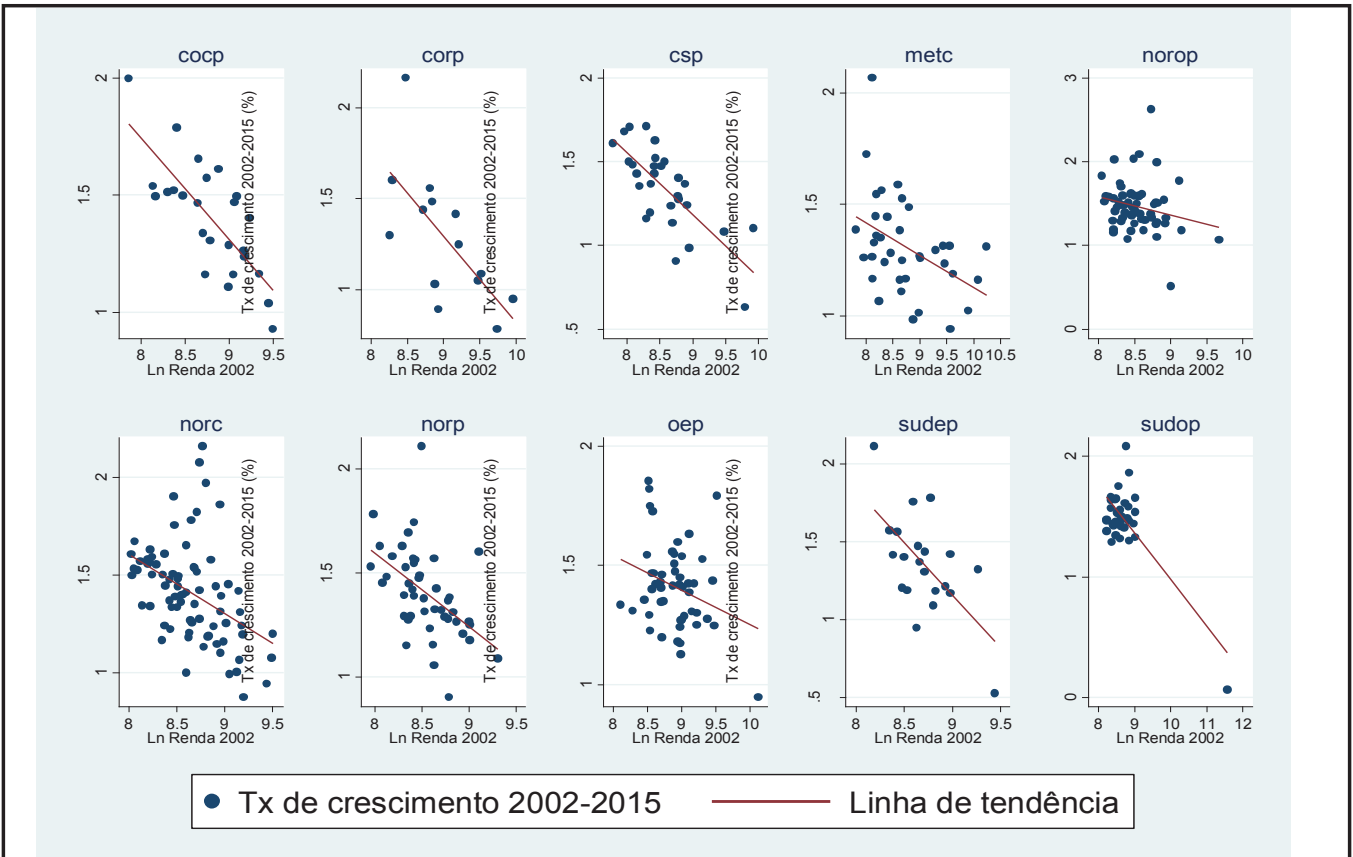

Fonte: Elaborada pelos autores a partir de resultados da pesquisa (2018).

Tabela A1 - Matriz de correlação amostral para diversas variáveis explicativas

\begin{tabular}{|c|c|c|c|c|c|c|c|}
\hline & Ln rpc 2002 & Ix_Analf & IDH_Edu & Perc_Esc & IDH_Long & Prop_Pobres & Dens_Dem \\
\hline Ln rpc 2002 & 1,000 & & & & & & \\
\hline Tx_ Analf & $-0,47139$ & 1,000 & & & & & \\
\hline IDH_Edu & 0,39994 & $-0,46956$ & 1,000 & & & & \\
\hline Perc_Esc & 0,27324 & $-0,32599$ & 0,61975 & 1,000 & & & \\
\hline IDH_Long & 0,27456 & $-0,45036$ & 0,52580 & 0,37851 & 1,00 & & \\
\hline Prop_Pobres & 0,39927 & 0,58542 & $-0,79495$ & $-0,56380$ & $-0,57651$ & 1,00 & \\
\hline Dens_Dem & 0,11889 & $-0,25761$ & 0,18068 & 0,32470 & 0,20081 & $-0,23822$ & 1,00 \\
\hline
\end{tabular}

Fonte: Elaborada pelos autores a partir de resultados da pesquisa (2018).

Tabela A2 - Teste de $\beta$-convergência condicional (modelo irrestrito) da renda per capita para os municípios do Paraná no período 2002-2015

\begin{tabular}{|c|c|c|c|c|c|c|c|c|c|c|c|}
\hline Variáveis & Pr & Cocp & Corp & Csp & Metc & Norop & Nore & Norp & Oep & Sudep & Sudop \\
\hline Ln $r p c 2002$ & $-0,341$ & $-0,459$ & $-0,298$ & $-0,358$ & $-0,188$ & $-0,190$ & $-0,376$ & $-0,628$ & $-0,253$ & $-0,797$ & $-0,404$ \\
\hline Tx_Analf & $-0,003$ & $-0,039$ & 0,034 & $-0,013$ & 0,024 & $-0,010$ & $-0,032$ & $-0,010$ & $-0,011$ & $-0,050$ & 0,006 \\
\hline ID $\bar{H} \_$Edu & 0,768 & $-1,581$ & 0,449 & 0,524 & 2,206 & $-0,035$ & $-0,254$ & 0,458 & 0,581 & 1,889 & 2,025 \\
\hline Perc_Esc & $-0,008$ & $-0,025$ & 0,180 & $-0,033$ & $-0,004$ & $-0,023$ & $-0,001$ & 0,008 & $-0,007$ & $-0,028$ & 0,019 \\
\hline IDH_Long & 0,221 & 3,148 & 3,107 & 1,475 & 1,131 & $-1,378$ & 0,073 & $-0,631$ & 0,303 & 1,556 & $-0,066$ \\
\hline Prop_Pobres & 0,001 & 0,005 & 0,022 & 0,008 & $-0,001$ & $-0,001$ & 0,006 & $-0,012$ & $-0,008$ & 0,007 & $-0,004$ \\
\hline Dens Dem & 0,00 & $-0,001$ & $-0,007$ & 0,006 & 0,00 & 0,005 & 0,00 & $-0,005$ & 0,00 & $-0,006$ & $-0,004$ \\
\hline Constante & 3,890 & 4,471 & $-0,168$ & 2,962 & 2,693 & 3,971 & 5,119 & 7,661 & 3,719 & 6,827 & 4,240 \\
\hline Jbservações & 399 & 25 & 14 & 29 & 37 & 61 & 79 & 46 & 50 & 21 & 37 \\
\hline R-quadrado & 0,265 & 0,816 & 0,823 & 0,677 & 0,377 & 0,099 & 0,254 & 0,492 & 0,220 & 0,551 & 0,762 \\
\hline
\end{tabular}

Fonte: Elaborada pelos autores a partir de resultados da pesquisa (2018) 
Tabela A3 - Proporção (\%) dos municípios por estratos de renda per capita no ano de 2002

\begin{tabular}{cccccccccccc}
\hline Classificacãa & Pr & Cocp & Corp & Csp & Metc & Norop & Norc & Norp & 0ep & Sudep & Sudop \\
\hline Muito Pobre & 8,52 & 12,00 & 0,00 & 20,69 & 18,92 & 6,56 & 8,86 & 13,04 & 2,00 & 0,00 & 0,00 \\
Pobre & 64,41 & 44,00 & 50,00 & 58,62 & 48,65 & 81,97 & 64,56 & 73,91 & 42,00 & 76,19 & 86,49 \\
Renda Média & 19,05 & 32,00 & 21,43 & 10,34 & 8,11 & 9,84 & 22,78 & 10,87 & 44,00 & 19,05 & 10,81 \\
Rico & 5,26 & 12,00 & 14,29 & 3,45 & 13,51 & 0,00 & 3,80 & 2,17 & 10,00 & 4,76 & 0,00 \\
Muito Rico & 2,76 & 0,00 & 14,29 & 6,90 & 10,81 & 1,64 & 0,00 & 0,00 & 2,00 & 0,00 & 2,70 \\
\hline
\end{tabular}

Fonte: Elaborada pelos autores a partir de resultados da pesquisa (2018).

Tabela A4 - Proporção (\%) dos municípios por estratos de renda per capita no ano de 2015

\begin{tabular}{cccccccccccc}
\hline Classificação & Pr & Cocp & Corp & Csp & Metc & Norop & Norc & Norp & Oep & Sudep & Sudop \\
\hline Muito Pobre & 4,01 & 0,00 & $\mathbf{0 , 0 0}$ & 6,90 & 16,22 & 6,56 & 1,27 & 4,35 & 2,00 & 0,00 & 0,00 \\
Pobre & 62,41 & 48,00 & 35,71 & 79,31 & 48,65 & 70,49 & 65,82 & 84,78 & 36,00 & 76,19 & 62,16 \\
Renda Média & 25,31 & 48,00 & 50,00 & 10,34 & 16,22 & 14,75 & 26,58 & 8,70 & 48,00 & 23,81 & 27,03 \\
Rico & 5,76 & 4,00 & 7,14 & 0,00 & 10,81 & 6,56 & 5,06 & 2,17 & 10,00 & 0,00 & 8,11 \\
Muito Rico & 2,51 & 0,00 & 7,14 & 3,45 & 8,11 & 1,64 & 1,27 & $\mathbf{0 , 0 0}$ & 4,00 & 0,00 & 2,70 \\
\hline
\end{tabular}

Fonte: Elaborada pelos autores a partir de resultados da pesquisa (2018).

Tabela A5 - Proporção (\%) dos municípios com taxas de crescimento da renda per capita acima e abaixo da média estadual no período 2002-2015

\begin{tabular}{cccccccccccc}
\hline Classificação & Pr & Cocp & Corp & Csp & Metc & Norop & Norc & Norp & Oep & Sudep & Sudop \\
\hline Acima & 62,91 & 60,00 & 42,86 & 58,62 & 37,84 & 70,49 & 64,56 & 58,70 & 66,00 & 57,14 & 89,19 \\
Abaixo & 37,09 & 40,00 & 57,14 & 41,38 & 62,16 & 29,51 & 35,44 & 41,30 & 34,00 & 42,86 & 10,81 \\
\hline
\end{tabular}

Fonte: Elaborada pelos autores a partir de resultados da pesquisa (2018).

Tabela A6 - Matriz de transição do estrato de renda per capita dos municípios do Paraná ${ }^{11}$ no período 2002-2015, em termos percentuais $(\%)$

\begin{tabular}{ccccccc}
\hline \multirow{2}{*}{ Estratos de renda per capita } & \multicolumn{5}{c}{$\mathbf{2 0 1 5}$} \\
\cline { 3 - 6 } & Muito Pobre & Pobre & Renda Média & Rico & Muito Rico \\
\hline \multirow{2}{*}{2002} & 26,47 & 73,53 & 0,00 & 0,00 & 0,00 \\
& Muito Pobre & 2,72 & 78,60 & 15,18 & 2,72 & 0,78 \\
Pobre & 0,00 & 27,63 & 64,47 & 7,89 & 0,00 \\
& Renda Média & 0,00 & 4,76 & 52,38 & 38,10 & 4,76 \\
Rico & 0,00 & 0,00 & 18,18 & 18,18 & 63,64 \\
\hline
\end{tabular}

Fonte: Elaborada pelos autores a partir de resultados da pesquisa (2018).

Nota: (1) A matriz de transição do período concenttra-se a nível estadual, não sendo efetuada a apresentação par as mesorregiões.

Figura A2 - Mesorregiões do estado do Paraná

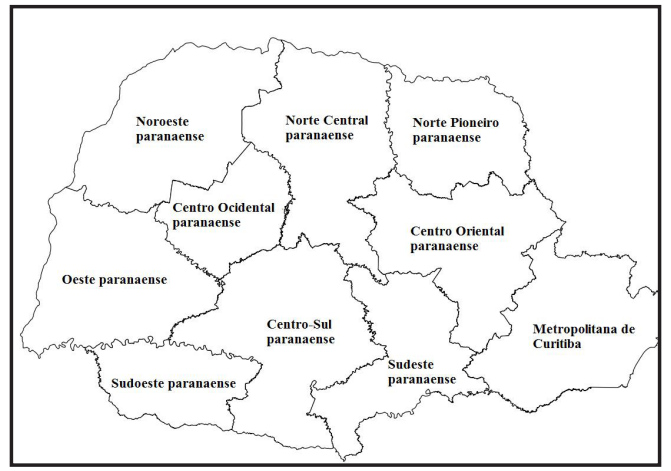

Fonte: Adaptada pelos autores a partir de IPARDES (2018) 